\title{
A cloud feedback emulator (CFE, version 1.0) for an intermediate complexity model
}

\author{
David J. Ullman ${ }^{1, a}$ and Andreas Schmittner ${ }^{1}$ \\ ${ }^{1}$ College of Earth, Ocean, and Atmospheric Sciences, Oregon State University, Corvallis, OR 97331 USA \\ ${ }^{a}$ now at: Northland College, Ashland, WI, USA \\ Correspondence to: David J. Ullman (dullman@ northland.edu)
}

Received: 20 August 2016 - Discussion started: 26 September 2016

Revised: 18 January 2017 - Accepted: 27 January 2017 - Published: 23 February 2017

\begin{abstract}
The dominant source of inter-model differences in comprehensive global climate models (GCMs) are cloud radiative effects on Earth's energy budget. Intermediate complexity models, while able to run more efficiently, often lack cloud feedbacks. Here, we describe and evaluate a method for applying GCM-derived shortwave and longwave cloud feedbacks from $4 \times \mathrm{CO}_{2}$ and Last Glacial Maximum experiments to the University of Victoria Earth System Climate Model. The method generally captures the spread in topof-the-atmosphere radiative feedbacks between the original GCMs, which impacts the magnitude and spatial distribution of surface temperature changes and climate sensitivity. These results suggest that the method is suitable to incorporate multi-model cloud feedback uncertainties in ensemble simulations with a single intermediate complexity model.
\end{abstract}

\section{Introduction}

The predominant trade-off in climate modeling is that of systematic complexity vs. computational expense. While comprehensive global climate models (GCMs) attempt to resolve the complex interactions between Earth systems, their computational expense limits the exploration of parametric uncertainty. Conversely, more simplified models, such as Earth system models of intermediate complexity (EMICs), can be employed for large-ensemble analysis of parametric variability, but their reliance on fixed boundary conditions or generalized parameterizations of earth processes may not capture all important feedbacks driving system dynamics.

One of the largest sources of inter-model spread in GCMbased climate projections is the magnitude and direction of radiative cloud feedbacks (Soden and Held, 2006; Dufrense and Bony, 2008; Tomassini et al., 2013; Vial et al., 2013). Clouds affect climate through their impacts on both shortwave (solar radiation mostly in the visible part of the spectrum) and longwave (terrestrial, infrared radiation) fluxes and therefore determine the sensitivity of GCMs to changes in radiative forcing (Andrews et al., 2012; Sherwood et al., 2014). Because clouds are more reflective than most other surfaces, an increase in clouds will reduce the amount of shortwave energy absorbed by the Earth and lead to cooling. Conversely, clouds ability to absorb upward longwave fluxes and re-radiate them back down causes warming at the surface (Hartmann and Short, 1980). The relative magnitude and net effect of these feedbacks depends on cloud altitude. For low clouds, which radiate longwave fluxes at a similar temperature as the surface, shortwave effects dominate and their net effect is cooling. High clouds, on the other hand, radiate at much colder temperatures than the surface, which can make the longwave effect dominate and lead to net warming (Hartmann et al., 1992). However, the cloud liquid water content and associated optical depth of high and low clouds likely also plays a role in the absorption and reflection of incoming shortwave fluxes (Tselioudis et al., 1992). Therefore, the net cloud feedback may be positive or negative feedback depending on whether low vs. high cloud cover, and cloud optical depth responds more to local and global temperature change. For state-of-the-art GCMs, the spread in cloud feedbacks is primarily driven by model differences in low cloud cover changes (Sherwood et al., 2014). In addition, the spread in GCM cloud feedbacks manifests in both the global mean as well as regional variability (Tomassini et al., 2013; Vial et al., 2013). This spatial variability likely has a profound im- 
pact on the magnitude of climate response to perturbations (Marvel et al., 2016).

Since EMICs use simplified atmospheric components, the cloud radiative forcing is typically fixed (Plattner et al., 2001; Joos et al., 2001; Driesschaert, 2005; Crucifix et al., 2002; Weaver et al., 2001). Therefore, the uncertainties in cloud feedbacks demonstrated in GCMs are typically neglected in the non-interactive cloud schemes of EMICs. Schmittner et al. (2011), e.g., hypothesized that their estimate of climate sensitivity, determined using the University of Victoria (UVic) EMIC and paleoclimate observations, resulted in a too narrow probability distribution due to the neglect of cloud feedback uncertainties. Here we describe and evaluate a new method for diagnosing and applying cloud feedbacks of state-of-the-art GCMs into an EMIC, thereby creating a computationally less-expensive emulator of more complex models.

\section{Methods}

\subsection{Model description}

The UVic Earth System Climate Model (Weaver et al., 2001) is an EMIC with a three-dimensional ocean general circulation model coupled to a dynamic-thermodynamic sea ice model, a two-dimensional single-layer energy-moisture balance atmosphere, and a dynamic land (Meissner et al., 2003) and vegetation model (Cox, 2001). Surface wind speeds used in the calculations of air-sea exchange and atmospheric transport of heat and moisture are prescribed in the model, thereby limiting variability in the atmospheric model. The model conserves heat and moisture without the need for a flux correction (Weaver et al., 2001). We employ version 2.9 of UVic (Eby et al., 2013), in which atmospheric heat diffusion varies with changes in global-mean surface air temperature; this modification has been shown to improve the latitudinal temperature gradient for the Last Glacial Maximum when compared with high-latitude proxy data (Fyke and Eby, 2012). All model components have a horizontal grid resolution of $1.8^{\circ}$ latitude by $3.6^{\circ}$ longitude, with 19 vertical levels in the ocean model increasing from $50 \mathrm{~m}$ thickness in the surface level to $590 \mathrm{~m}$ thickness in the deepest grid cell.

The net radiative balance (NETRAD) at the top of the atmosphere (TOA) is the difference between the net shortwave radiation $\left(\mathrm{SW}_{\mathrm{TOA}}\right)$ and the outgoing longwave radiation (OLW):

$\mathrm{NETRAD}=\mathrm{SW}_{\mathrm{TOA}}-\mathrm{OLW}$.

Clouds impact $\mathrm{SW}_{\mathrm{TOA}}$ through prescribed monthly fields of atmospheric albedo $\left(\alpha_{\text {atm }}\right)$ :

$$
\begin{aligned}
\mathrm{SW}_{\mathrm{TOA}}= & \mathrm{SW}_{\mathrm{in}, \mathrm{TOA}}-\mathrm{SW}_{\mathrm{in}, \mathrm{TOA}} \times \alpha_{\mathrm{atm}}-\mathrm{SW}_{\mathrm{in}, \mathrm{TOA}} \\
& \times\left(1-\alpha_{\mathrm{atm}}\right) \times \alpha_{\mathrm{sfc}} \times \tau^{2},
\end{aligned}
$$

where $S$ is the flux of incoming (incident) solar radiation energy per unit area $\left(\mathrm{W} \mathrm{m}^{-2}\right)$ at the top of the atmosphere (with seasonal and latitudinal variation), $\tau$ is a constant atmospheric transmission coefficient (0.77), and $\alpha_{\mathrm{sfc}}$ is the surface albedo. The second term of Eq. (2) represents the proportion of incoming SW radiation that is immediately reflected by clouds, whereas the third term represents the portion that is reflected by the surface, which passes through the atmosphere twice. During its first (downward) pass, $\mathrm{SW}_{\mathrm{TOA}} \times$ $\left(1-\alpha_{\mathrm{atm}}\right) \times(1-\tau)$ is absorbed by the atmosphere. During its second (upward) pass, $\mathrm{SW}_{\mathrm{TOA}} \times\left(1-\alpha_{\mathrm{atm}}\right) \times(1-\tau) \times$ $\alpha_{\text {sfc }} \times(1-\tau)$ is absorbed. All variables except for $\tau$ vary over space and time, but while $\alpha_{\text {sfc }}$ is allowed to evolve with changes in surface model components (sea ice, snow cover, vegetation, etc.), $\alpha_{\mathrm{atm}}$ is a fixed boundary condition at monthly resolution to resolve seasonal changes in regional cloud cover. In the control version of UVic, $\alpha_{\text {atm }}$ is estimated with the following relationship:

$\alpha_{\mathrm{atm}}=\frac{f \times \alpha_{\mathrm{plt}}-\alpha_{\mathrm{sfc}}}{1-\alpha_{\mathrm{sfc}} \times \tau^{2}}$,

where

$\alpha_{\mathrm{plt}}=\frac{\mathrm{SW}_{\mathrm{out}, \mathrm{TOA}}}{\mathrm{SW}_{\mathrm{in}, \mathrm{TOA}}}$,

$\alpha_{\mathrm{sfc}}=\frac{\mathrm{SW}_{\mathrm{out}, \mathrm{sfc}}}{\mathrm{SW}_{\mathrm{in}, \mathrm{sfc}}}$,

where the planetary $\left(\alpha_{\mathrm{plt}}\right)$ and surface albedo $\left(\alpha_{\mathrm{sfc}}\right)$ are calculated using the incoming and outgoing shortwave satellite observational measurements at the surface and top of the atmosphere from the Earth Radiation Budget Experiment (ERBE; Barkstrom, 1984; Barkstrom and Smith, 1986; Ramanathan et al., 1989). This $\alpha_{\text {atm }}$ relationship is directly derived from Eq. (2) so as to be internally consistent with the radiative balance relationship from the UVic model. The variable $f$ in Eq. (3) is a constant planetary albedo adjustment factor to account for radiative imbalances that arise in the implementation of the derived $\alpha_{\text {atm }}$.

The OLW is parameterized in UVic using an empirical relationship (Thompson and Warren, 1982; Weaver et al., 2001) that determines clear-sky OLW as a function of on surface relative humidity $(\mathrm{RH})$ and temperature (SAT):

$$
\begin{aligned}
\mathrm{OLW}= & c_{00}+c_{01} \mathrm{RH}+c_{02} \mathrm{RH}^{2} \\
& +\left(c_{10}+c_{11} \mathrm{RH}+c_{12} \mathrm{RH}^{2}\right) \mathrm{SAT} \\
& +\left(c_{20}+c_{21} \mathrm{RH}+c_{22} \mathrm{RH}^{2}\right) \mathrm{SAT}^{2} \\
& +\left(c_{30}+c_{31} \mathrm{RH}+c_{32} \mathrm{RH}^{2}\right) \mathrm{SAT}^{3} \\
& +\Delta F_{2 \times \mathrm{xO}_{2}} \ln \frac{\left[\mathrm{CO}_{2}\right]_{t}}{\left[\mathrm{CO}_{2}\right]_{o}},
\end{aligned}
$$

where the final term adjusts OLW for a change in the atmospheric $\mathrm{CO}_{2}$ concentrations. The value of 
$\Delta F_{2 \times \mathrm{CO}_{2}}=5.35 \mathrm{~W} \mathrm{~m}^{-2}$ is selected as the radiative forcing associated with $3.71 \mathrm{~W} \mathrm{~m}^{-2}$ (IPCC, 2001). The constants $\left(c_{x x}\right)$ are provided by Thompson and Warren (1982). Since this was originally estimated as a clear-sky relationship, the effect of clouds on the OLW radiative balance is not explicitly included.

\subsection{CERES update to atmospheric albedo boundary conditions}

Because of discontinuities in satellite coverage, missing data, and poor resolution, the Clouds and the Earth's Radiant Energy System (CERES; Wielicki et al., 1996) was launched in late 1999 to better observe the Earth's radiative balance (Fasullo and Trenberth, 2008). The CERES experiment uses an updated satellite architecture and provides higher spatial resolution observations over a longer time domain (2000-2013 for CERES compared with 1985-1989 for ERBE), thereby providing more robust modern climatology on the impact of clouds on atmospheric albedo (Wielicki et al., 1996). In addition, the duration of the ERBE experiment between 1985 to 1989 spans a somewhat large El Niño event (1987), which may bias the equatorial Pacific toward enhanced cloudiness in the calculation of atmospheric albedo climatology using the ERBE data (Cess et al., 2001).

In this paper, we use the climatology (2000-2013) of CERES surface and top of the atmosphere shortwave fluxes to better estimate $\alpha_{\text {atm }}$ boundary conditions in UVic (using Eq. 3). Under low-light conditions (winter, high-latitudes), satellite-derived estimates of incoming SW are small, which occasionally results in values of $\alpha_{\mathrm{plt}}$ and $\alpha_{\mathrm{sfc}}$ that are greater than 1 . Therefore, we limit $\alpha_{\mathrm{plt}}$ and $\alpha_{\mathrm{sfc}}$ to values less than 1, which ensures that $\alpha_{\text {atm }}$ is within appropriate limits.

An ensemble of control simulations was performed using the new CERES-based estimates of $\alpha_{\text {atm }}$ with varying values of the $f$ parameter in Eg. (3). From the resulting equilibrium simulations, a value of $f=0.95$ in Eq. (3) was selected in order to match 20th century global mean temperature data estimates of $\sim 13.9^{\circ} \mathrm{C}$ (NOAA, 2016) in a UVic control simulation. This final estimate of CERES-based $\alpha_{\text {atm }}$ was smoothed and regridded to the UVic grid.

Figure 1 compares the annual-mean values of $\alpha_{\mathrm{atm}}$ as derived from the ERBE and CERES datasets. In the tropics, the ERBE-based estimates of $\alpha_{\text {atm }}$ generally match those of the CERES-based values (Fig. 1). In the high latitudes, however, the ERBE-based $\alpha_{\text {atm }}$ values are generally higher than the CERES-based values. Such differences are likely related to improvement in sampling orbit of the CERES satellite and the associated reduction in zenith angle-dependent biases, which may result in large errors in the top-of-the-atmosphere flux measurements in the ERBE data (Loeb et al., 2009). Furthermore, the use of CERES-based estimates of $\alpha_{\text {atm }}$ provides an improvement in UVic, particularly at high latitudes.

\subsection{Innovations}

With the use of CERES-based $\alpha_{\text {atm }}$ estimates, the UVic model now includes an updated effect of clouds on the Earth's shortwave radiative balance. However, the control UVic model design does not incorporate any change in the shortwave or longwave radiative effect of clouds due to changes in temperature. This lack of cloud feedbacks may significantly limit the ability of UVic to capture global temperature in perturbed simulations. Here, we provide a simple method of diagnosing cloud radiative forcings from GCM results of the Coupled Model Intercomparison Project 5 (CMIP5) and Paleoclimate Model Intercomparison Project 3 (PMIP3) archives (Braconnot et al., 2011; Taylor et al., 2012) and incorporate the associated shortwave and longwave cloud feedbacks into UVic for both 4 times $\mathrm{CO}_{2}$ $\left(4 \mathrm{xCO}_{2}\right)$ and Last Glacial Maximum (LGM) climate simulations. Reanalysis of satellite observations suggests that the range of CMIP5 models present widespread agreement with cloud data, both in spatial extent and vertical distribution, across the historical record (Norris et al., 2016). We have selected model output from seven GCMs: Community Climate System Model version 4 (abbreviated as CCSM), Centre National de Recherches Meteorologiques version CM5 (CNRM), Goddard Institute for Space Sciences Model E2R (GISS), Institute Pierre Simon Laplace CM5A-LR (IPSL), Model for Interdisciplinary Research on Climate-Earth System Model (MIROC), Max Planck Institut model ESM-P (MPI), Meteorological Research Institute model CGCM3 (MRI). These models were chosen because they have results for both $4 \times \mathrm{CO}_{2}$ and LGM simulations and all of the relevant variables for calculating shortwave and longwave cloud feedbacks (see below). The following innovations demonstrate how we employ UVic as a cloud feedback emulator (CFE version 1.0; henceforth CFE) of the full GCMs.

\subsubsection{Shortwave cloud feedbacks in UVic}

Since UVic incorporates the shortwave impact of clouds through atmospheric albedo, we assess the shortwave cloud feedback as the change in $\alpha_{\text {atm }}$ due to the change in temperature in each of the GCM simulations. Albedo anomalies are not mathematically additive; therefore, we first calculate $\alpha_{\text {atm }}$ for each perturbed state $\left(4 \times \mathrm{CO}_{2}, \mathrm{LGM}\right)$ by adding GCM anomalies of each of the individual fluxes to the CERES observations:

$$
\begin{aligned}
& \mathrm{SW}_{\mathrm{in}, \mathrm{TOA}, \mathrm{GCM}}=\left(\mathrm{SW}_{\mathrm{in}, \mathrm{TOA}, \text { perturbed }}-\mathrm{SW}_{\mathrm{in}, \mathrm{TOA}, \mathrm{control}}\right) \\
& +\mathrm{SW}_{\text {in,TOA,CERES }} \text {, } \\
& \mathrm{SW}_{\text {out }, \mathrm{TOA}, \mathrm{GCM}}=\left(\mathrm{SW}_{\text {out }, \mathrm{TOA}, \text { perturbed }}-\mathrm{SW}_{\text {out }, \mathrm{TOA}, \text { control }}\right) \\
& +\mathrm{SW}_{\text {out }, \text { TOA,CERES }} \text {, } \\
& \mathrm{SW}_{\mathrm{in}, \mathrm{sfc}, \mathrm{GCM}}=\left(\mathrm{SW}_{\mathrm{in}, \mathrm{sfc}, \text { perturbed }}-\mathrm{SW}_{\mathrm{in}, \mathrm{sfc}, \mathrm{control}}\right)
\end{aligned}
$$

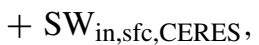

$$
\begin{aligned}
& \mathrm{SW}_{\text {out }, \mathrm{sfc}, \mathrm{GCM}}=\left(\mathrm{SW}_{\text {out,sfc,perturbed }}-\mathrm{SW}_{\text {out }, \text { sfe,control }}\right)
\end{aligned}
$$




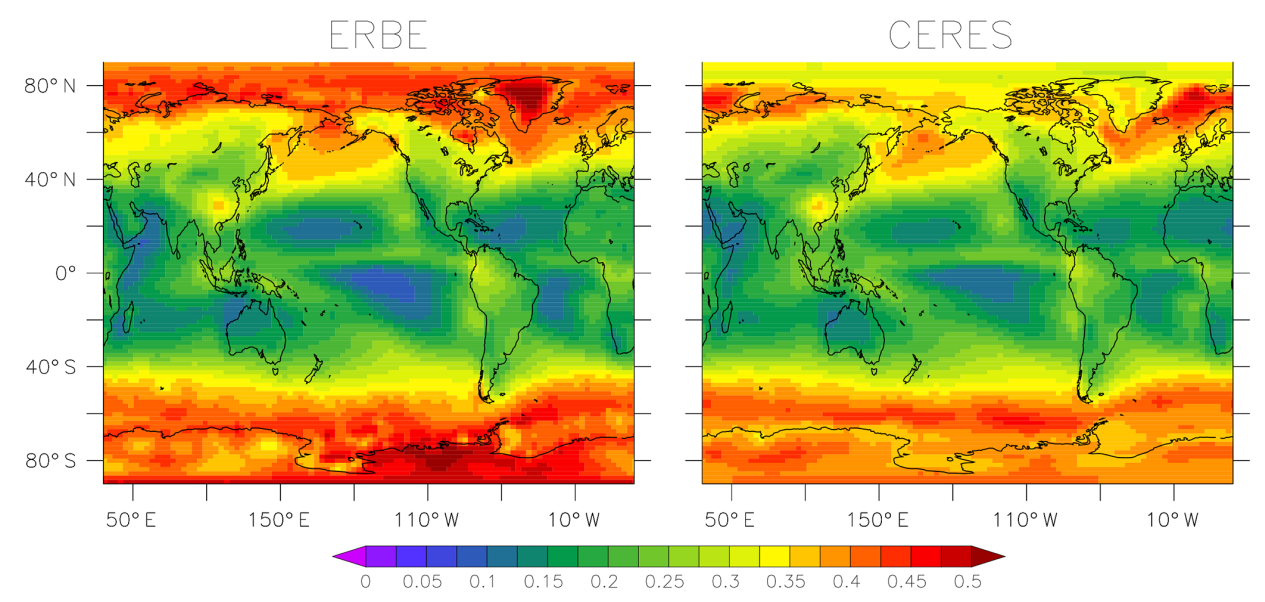

Figure 1. Comparison of annual-averaged atmospheric albedo $\left(\alpha_{\mathrm{atm}}\right)$ as calculated using Eq. (3) and the climatology of ERBE (left) and CERES (right) data.

$$
+\mathrm{SW}_{\text {out,sfc,CERES. }}
$$

For each of the variables, we have calculated a 12-month climatology (separate averaging for each month) that is assessed over the final 10 years of the 150 year transient $4 \times \mathrm{CO}_{2}$ simulations, the final 100 years of the LGM equilibrium simulations, and the final 100 years of the equilibrium control simulations. The anomaly perturbed values of each of the shortwave fluxes (Eqs. 7-10) are then used to calculate an $\alpha_{\text {atm,perturbed }}$ for each of the perturbed GCM simulations using Eqs. (3)-(5).

Again, because albedo values are not additive, we calculate the albedo anomaly as the ratio of the atmospheric albedo of the GCM perturbed state to CERES-derived atmospheric albedo. Therefore, the $\alpha_{\mathrm{atm}}$ feedback $\left(\alpha_{\mathrm{atm}} \mathrm{FB}\right)$ is this albedo anomaly divided by the change in temperature:

$\alpha_{\text {atm }} \mathrm{FB}=\frac{\left[\alpha_{\text {atm,perturbed }} / \alpha_{\text {atm,CERES }}\right]-1}{\mathrm{SAT}_{\text {perturbed }}-\mathrm{SAT}_{\text {control }}}$

The subtraction of 1 in the numerator is necessary such that when there is no change in $\alpha_{\text {atm }}\left(\alpha_{\text {atm,perturbed }}=\alpha_{\text {atm,CERES }}\right)$, then there is no atmospheric albedo feedback. This $\alpha_{\text {atm }}$ feedback is calculated as a 12-month climatology at each grid cell of the seven GCMs that are sampled in this analysis (Figs. 2, 3). Positive (negative) values for this atmospheric albedo feedback indicate a negative (positive) shortwave cloud feedback since increases in temperature cause an increase (decrease) in atmospheric albedo, which cools (warms) the surface. The magnitude of these atmospheric albedo feedbacks varies considerably among the GCMs and between perturbed climate states $\left(4 \times \mathrm{CO}_{2}\right.$ vs. $\left.\mathrm{LGM}\right)$, which is consistent with the large spread in cloud shortwave feedbacks found in previous studies (Tomassini et al., 2013; Vial et al., 2013). For example, GISS-E2-R shows a strongly positive atmospheric albedo feedback from the $4 \times \mathrm{CO}_{2}$ results, whereas IPSLCM5A-LR generally shows a strongly negative atmospheric albedo feedback, particularly in the tropics (Fig. 2).
The innovation to UVic is the application of these GCMdiagnosed $\alpha_{\text {atm }}$ feedbacks to the shortwave radiative balance. First, we calculate a SAT climatology from a long-term control simulation of UVic that uses $\alpha_{\text {atm,CERES }}$ as the control atmospheric albedo. Then at each time step $(t)$ of a model simulation, we calculate the difference in surface air temperature from this control monthly climatology, and perturb atmosphere albedo at each grid cell using the GCM-derived $\alpha_{\mathrm{atm}} \mathrm{FB}$ of Eq. (11):

$\begin{aligned} \alpha_{\mathrm{atm}}(t)= & {\left[\alpha_{\mathrm{atm}} \mathrm{FB} \times\left[\mathrm{SAT}(t)-\mathrm{SAT}_{\mathrm{ctl}}\right]+1\right] } \\ & \times \alpha_{\mathrm{atm}, \mathrm{CERES}} .\end{aligned}$

The above calculation is done at every time step and each grid cell, allowing for spatially and monthly specific atmospheric albedo feedbacks as diagnosed from the GCMs.

\subsubsection{Longwave cloud feedbacks in UVic}

Because UVic lacks a longwave cloud feedback in the calculation of OLW, we provide an additional term to Eq. (6), which now includes the OLW due to changes in the cloud longwave effect in the GCM simulations. First, we diagnose the outgoing longwave radiation at the top of the atmosphere from the GCM output:

$\mathrm{OLW}_{\text {cloud }}=\mathrm{OLW}_{\text {total }}-\mathrm{OLW}_{\text {clear sky }}$.

The outgoing longwave cloud feedback is therefore the cloud longwave forcing anomaly divided by temperature anomaly:

$\mathrm{OLW}_{\text {cloud }} \mathrm{FB}=\frac{\mathrm{OLW}_{\text {cloud,perturbed }}-\mathrm{OLW}_{\text {cloud,control }}}{\mathrm{SAT}_{\text {perturbed }}-\mathrm{SAT}_{\text {control }}}$,

as diagnosed from results of the GCM perturbed simulations. These outgoing longwave cloud feedbacks are calculated as monthly climatologies at each grid cell, and are assessed separately for both the $4 \times \mathrm{CO}_{2}$ and LGM perturbed 

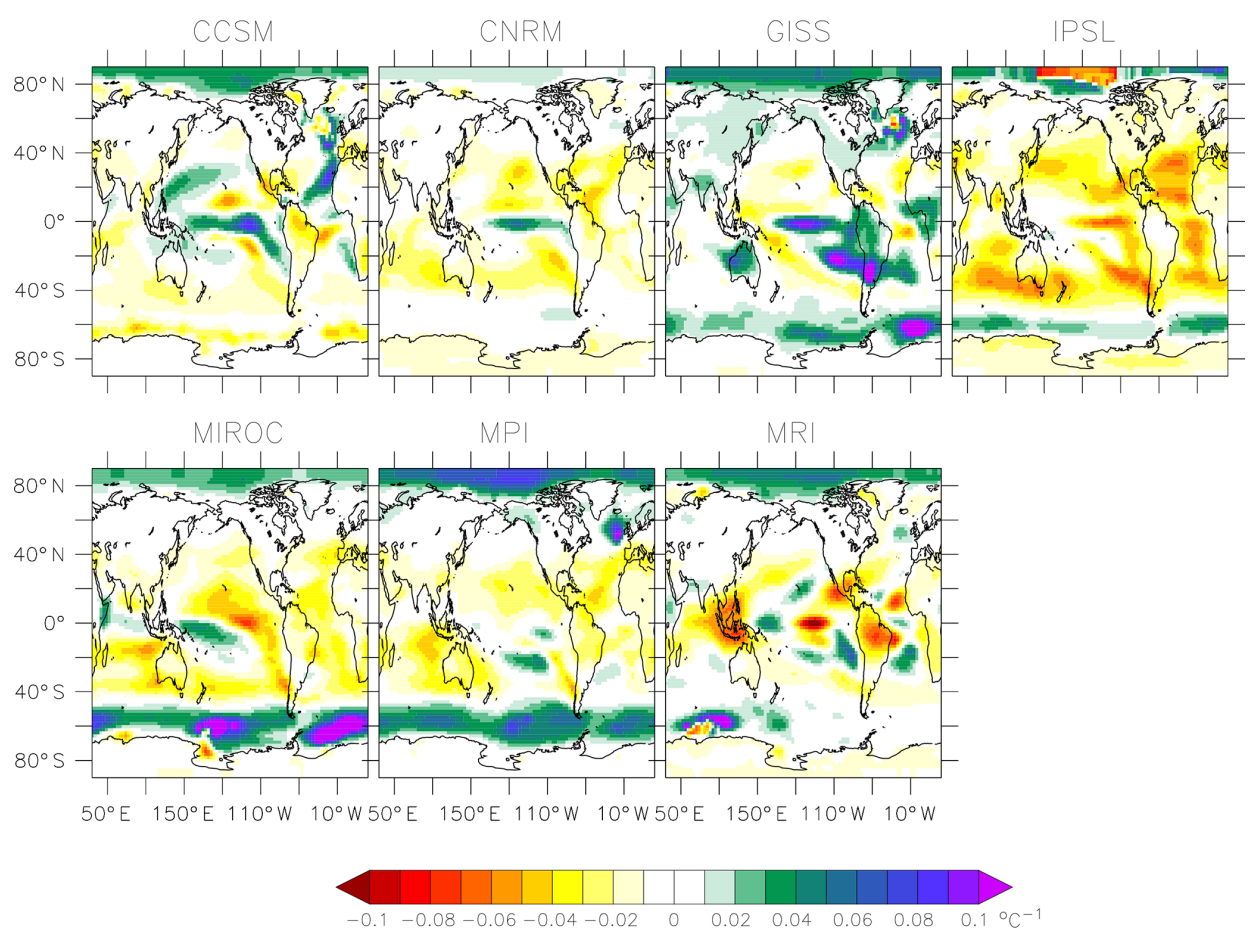

Figure 2. Maps of annual-mean atmospheric albedo feedback term $\left(\alpha_{\mathrm{atm}} \mathrm{FB}\right)$, as calculated using Eq. (11) and the $4 \times \mathrm{CO}_{2}$ results of the seven CMIP5 models discussed in the text. Units are albedo fraction change per ${ }^{\circ} \mathrm{C}$.

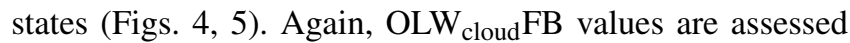
using the 12-month climatologies assessed over the final 10 years of the 150 -year transient $4 \times \mathrm{xCO} 2$ simulations, the final 100 years of the LGM equilibrium simulations, and the final 100 years of the equilibrium control simulations. We note that by calculating the OLW cloud radiative effect using the total OLW minus clear-sky OLW (Eq. 13), we are implicitly including the effects of cloud masking and rapid cloud adjustments (Zelinka et al., 2013). Including both of these effects has been shown to reduce both LW and SW cloud feedbacks relative to a more explicit cloud radiative kernel method (Zelinka et al., 2012, 2013). Both effects may limit the magnitude of the total cloud feedback.

Most models show more areas of positive $\mathrm{OLW}_{\text {cloud }} \mathrm{FB}$. This indicates a negative climate feedback since increasing temperatures lead to more OLW, which cools the surface. Again, the outgoing longwave cloud feedbacks vary considerable between models and climate state. The largest variability in OLW cloud feedbacks between models exists in the tropics, which is consistent with prior results suggesting that model differences in convective mixing and resulting cloud height greatly impacts the magnitude and direction of cloud feedbacks (Sherwood et al., 2014). Generally, the OLW cloud feedback is stronger in magnitude for the LGM state (Fig. 5) than for the $4 \times \mathrm{CO}_{2}$ state.

Similar to the inclusion of the atmospheric albedo feedbacks in UVic, we multiply the outgoing longwave cloud feedback by the temperature difference from the long-term control UVic simulation:

$\operatorname{OLW}_{\text {cloud }}(t)=\mathrm{OLW}_{\text {cloud }} \mathrm{FB} \times\left[\mathrm{SAT}(t)-\mathrm{SAT}_{\mathrm{ctl}}\right]$.

This OLW $_{\text {cloud }}$ term is calculated at each time step and grid cell in the model and is added to the OLW parameterization (Eq. 6) as an additional cloud longwave feedback term.

\subsection{Numerical experiments}

To estimate how well our CFE captures the original cloud radiative effects from the GCMs, we present an ensemble of CFE control and perturbed experiments $\left(4 \times \mathrm{CO}_{2}\right.$ and $\left.\mathrm{LGM}\right)$ that use the $\alpha_{\text {atm }}$ and OLW $_{\text {cloud }}$ feedbacks diagnosed from each of the seven GCMs employed in this analysis. Because our diagnosed cloud feedbacks differ between the $4 \times \mathrm{CO}_{2}$ and LGM climate states (Figs. 2-5), we ran two separate preindustrial control simulations for each ensemble member: one with $4 \times \mathrm{CO}_{2}$ cloud feedbacks (ctl4x) and one with LGM cloud feedbacks (ctlLGM). Indeed, the inclusion of these cloud feedbacks in the control climate state leads to slight differences in control global mean temperature, indicating that separate controls are necessary in the calculation of resulting radiative feedbacks. Therefore, we present the results from 28 separate CFE simulations: four simulations (ctl4x, ctlLGM, $4 \times \mathrm{CO}_{2}$, LGM) for each of the seven GCM-derived cloud feedbacks.

Preindustrial control and LGM simulations with each of the GCM-derived cloud feedbacks were run to extended 

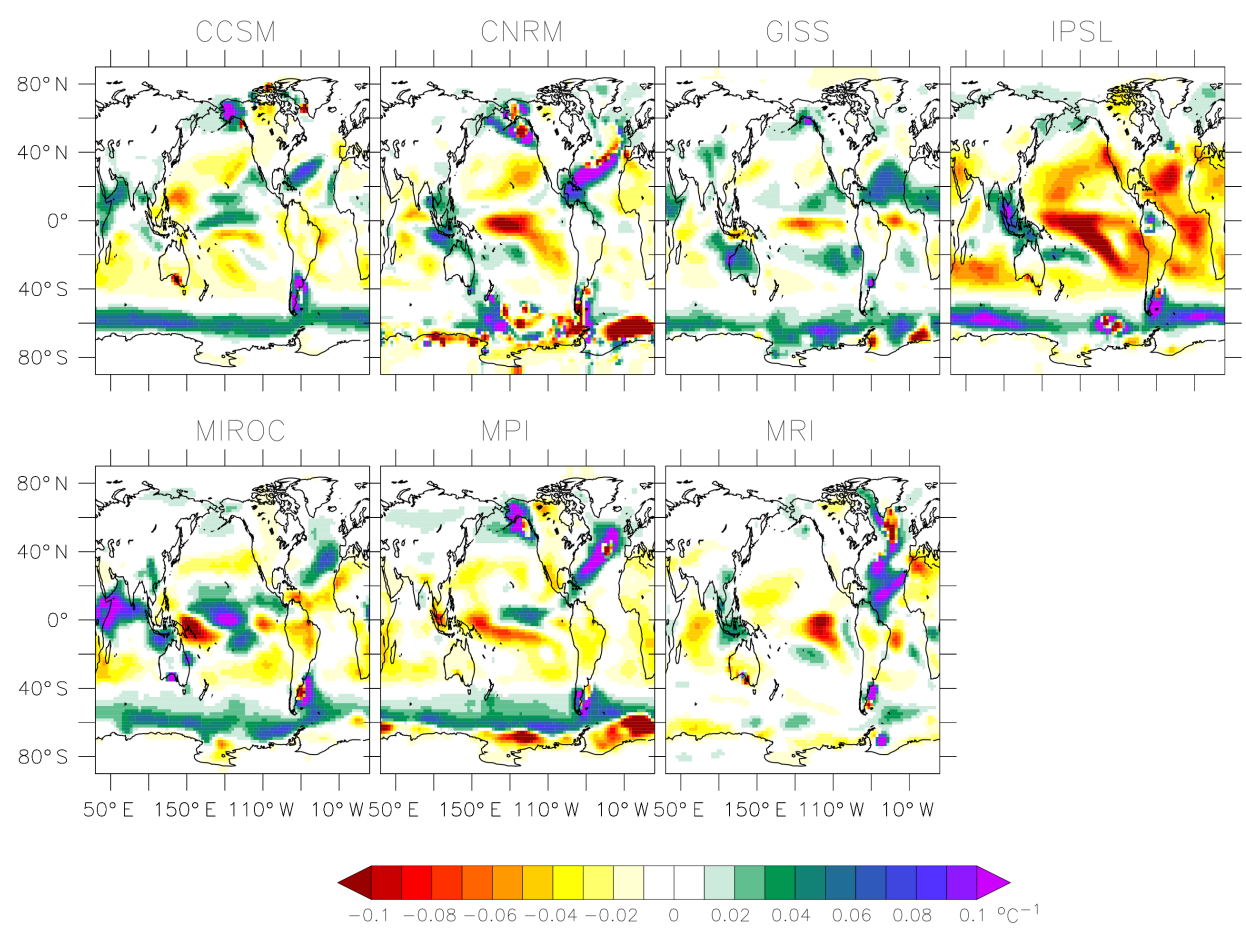

Figure 3. Maps of annual-mean atmospheric albedo feedback term $\left(\alpha_{\mathrm{atm}} \mathrm{FB}\right)$, as calculated using Eq. (11) and the LGM results of the 7 PMIP3 models discussed in the text. Units are albedo fraction change per ${ }^{\circ} \mathrm{C}$. Note that because the LGM represents a period of global cooling (Braconnot et al., 2012), the direction of change in $\alpha_{\mathrm{atm}}$ is opposite that shown in these figures.

equilibrium ( $>2000$ years) to be certain of minimal model drift (global mean SAT trend $<0.04^{\circ} \mathrm{C}$ per 100 years). Both $4 \times \mathrm{CO}_{2}$ and LGM simulations follow the CMIP5/PMIP3 protocol (Braconnot et al., 2011; Taylor et al., 2012) as closely as possible as these are the boundary conditions used in the original GCM simulations. Our $4 \times \mathrm{CO}_{2}$ simulations use modern boundary conditions, an instantaneous increase in atmospheric $\mathrm{CO}_{2}$ concentration to $1120 \mathrm{ppm}$, and a simulation length of 150 years, starting from the end of the preindustrial control simulation (ctl4x). Our LGM simulations have reduced greenhouse gas concentrations (atmospheric $\mathrm{CO}_{2}=185 \mathrm{ppm}$; radiative forcing adjusted for appropriate $\mathrm{CH}_{4} / \mathrm{N}_{2} \mathrm{O}$ concentrations; Schmittner et al., 2011), altered orbital state, full glacial ice sheet extent/topography (Peltier, 2004), modified river pathways, and +1 PSU (practical salinity unit) increase in mean ocean salinity. In addition, we apply LGM surface wind stress anomalies that are diagnosed from the LGM GCM results (Muglia and Schmittner, 2015). Wind stress anomalies at the end of the CMIP5 $4 \times \mathrm{CO}_{2}$ simulations are small; therefore, we use the prescribed wind stress fields of the control UVic 2.9 model (from NCEP reanalysis) in our $4 \times \mathrm{CO}_{2}$ simulations.

\section{Results}

\subsection{Assessment of GCM-diagnosed cloud feedbacks}

Across the historical record with a warming climate, the cloud trends in CMIP5 models have been shown to be in agreement with satellite observations, with robust reductions in cloudiness across the mid-latitude and tropics, as well as an increase in cloud top height at all latitudes (Norris et al., 2016). Our calculated $4 \times \mathrm{CO}_{2}$ atmospheric albedo feedbacks are consistent with these observations, generally showing a reduction in $\alpha_{\text {atm }}$ in the mid-latitudes and tropics (Fig. 2). Only one model (GISS) shows an increase in $\alpha_{\text {atm }}$ across the $4 \times \mathrm{CO}_{2}$ simulations. Most of the $4 \times \mathrm{CO}_{2}$ GCM-diagnosed $\alpha_{\text {atm }}$ feedbacks seem to suggest an increase in $\alpha_{\text {atm }}$ in the high-latitudes with warming (particularly over the Southern Ocean), which is likely related to a poleward shift in the storm tracks due to warming (Lu et al., 2007; Norris et al., 2016).

The $4 \times \mathrm{CO}_{2}$ GCM-derived $\mathrm{OLW}_{\text {cloud }}$ feedbacks are also most prominent in the tropics with considerable variability in the location, magnitude, and direction of peak feedback (Fig. 4). However, all models show a negative OLW $_{\text {cloud }}$ feedback across the equatorial Pacific and a positive OLW $_{\text {cloud }}$ feedback over the Indonesia Archipelago, South America, and off the Equator. Outside of the tropics, most models show positive OLW $_{\text {cloud }}$ feedbacks in the 

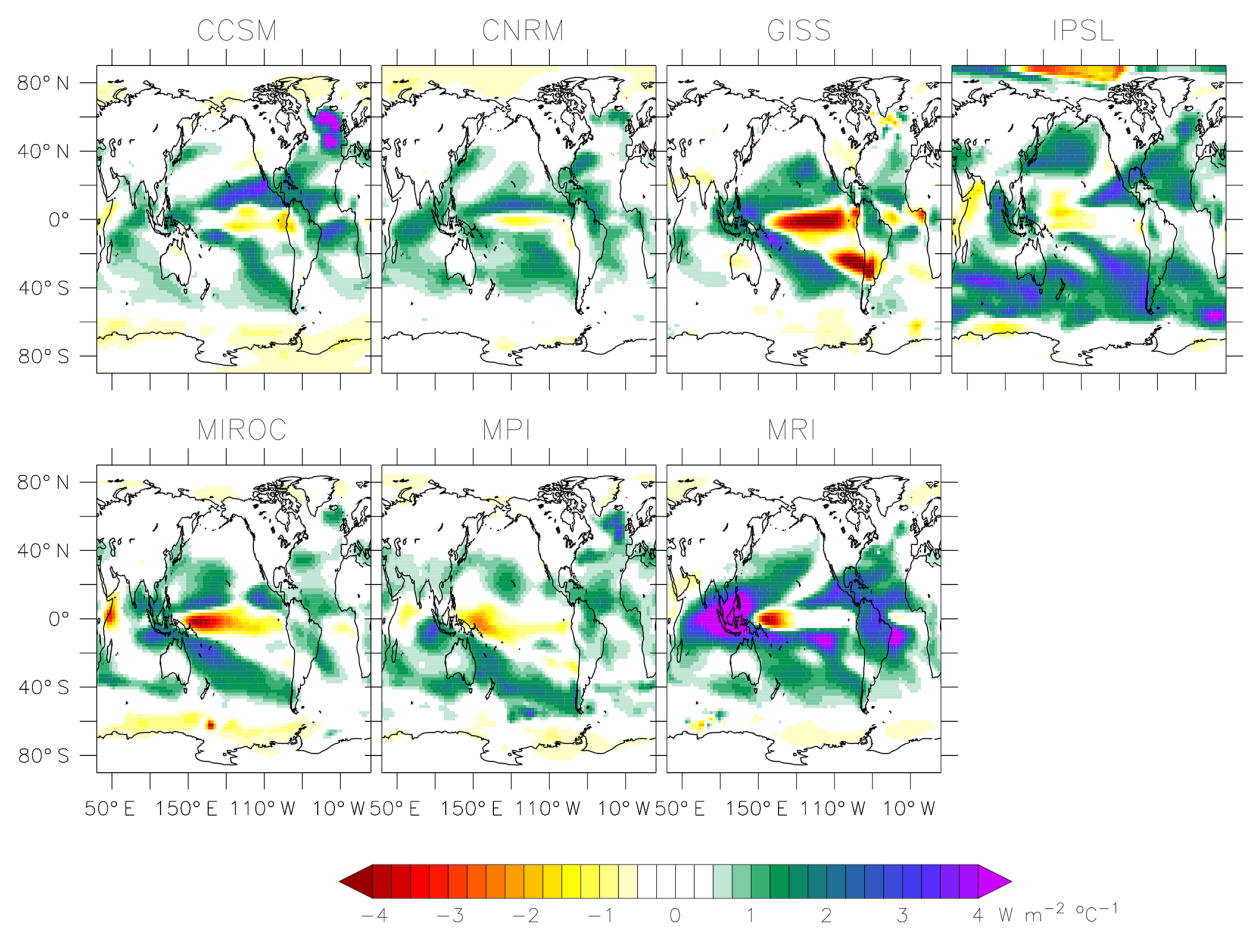

Figure 4. Maps of annual-mean outgoing longwave feedback term $\left(\mathrm{OLW}_{\text {cloud }} \mathrm{FB}\right)$, as calculated using Eq. (14) and the $4 \times \mathrm{CO}_{2}$ results of the 7 CMIP5 models discussed in the text. Units are $\mathrm{W} \mathrm{m}^{-2}{ }^{\circ} \mathrm{C}^{-1}$.

mid-latitudes and slight negative feedbacks in the polar regions. These data are consistent with observations of increased cloud top height (Norris et al., 2016), as regions with enhanced cloudiness (increased $\alpha_{\text {atm }}$, Fig. 2) also typically show decreased OLW (Fig. 4).

For the LGM, GCM-derived cloud feedbacks are less coherent. Nearly all models show large changes in the tropical $\alpha_{\text {atm }}$ feedback, particularly across the equatorial Pacific and Indonesian Archipelago (Fig. 3). Such changes may be suggestive of changes in the position of the intertropical convergence zone (ITCZ)-associated changes in deep convective cloud systems that are specific to each model (Braconnot et al., 2007; Arbuszewski et al., 2013). In addition, nearly all GCM-derived feedbacks show a reduction in $\alpha_{\text {atm }}$ over the North Atlantic (note that LGM cooling indicates that direction of feedback change is opposite that shown in Fig. 3), which may be indicative of a shift in the position of the Gulf Stream seen in some models (Otto-Bliesner et al., 2006). The prominent feature in the LGM GCM-derived $\mathrm{OLW}_{\text {cloud }}$ feedback is a large reduction in the tropics (green-blue-purple colors in Fig. 5), which is likely related to the reduction in tropical convection due to lower sea surface temperatures (Yin and Battisti, 2001). However, this spatial extent and magnitude of reduction in $\mathrm{OLW}_{\text {cloud }}$ for the LGM vary appreciably among the GCMs.

\subsection{Radiative balance in $\mathrm{CFE} 4 \times \mathrm{CO}_{2}$ simulation}

To compare the global radiative balance of CFE with that of the GCMs, we calculate the total change in TOA shortwave and longwave fluxes per global mean surface temperature change from the final 10 years of the 150 -year $4 \times \mathrm{CO}_{2}$ simulations (relative to the control simulation) and compare the raw GCM results with our cloud feedback-forced CFE simulations (Fig. 6). The changes in longwave fluxes include the $\mathrm{CO}_{2}$ forcing, which may differ by $\sim 15 \%$ between models (Andrews et al., 2012). Because the forcing is included in the longwave fluxes, the flux/temperature ratios shown in Fig. 6 are not a true "feedback", strictly speaking; therefore, we use the term "radiative-temperature response." However, variations in the forcings are presumably relatively small compared to variations in feedbacks. The shortwave flux / temperature ratios in Fig. 6 are true feedbacks and consistent with numbers reported previously (Tomassini et al., 2013).

In general, the spread of TOA shortwave and longwave radiative-temperature response in the $4 \times \mathrm{CO}_{2} \mathrm{CFE}$ simulations matches that of the original GCM results (Fig. 6) and is consistent with previous work (Tomassini et al., 2013). For instance, the IPSL model exhibits the largest positive shortwave and largest negative longwave radiative-temperature response in the GCM results, which is also captured in our CFE simulations (Figs. 2, 4). Conversely, the GISS model is the only simulation to show a negative shortwave and 

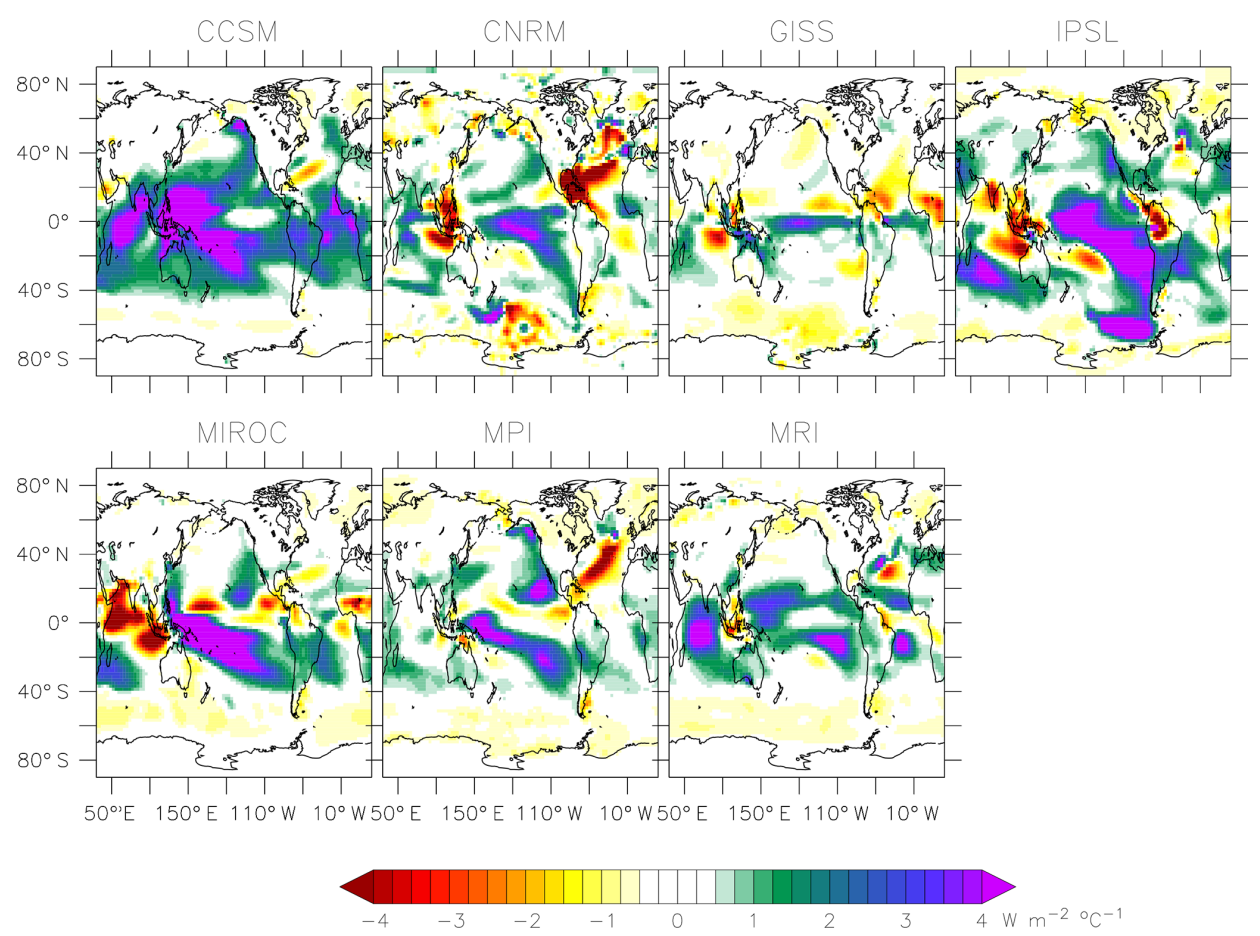

Figure 5. Maps of annual-mean outgoing longwave feedback term (OLW cloud $\mathrm{FB})$, as calculated using Eq. (14) and the LGM results of the 7 PMIP3 models discussed in the text. Units are $\mathrm{W} \mathrm{m}^{-2}{ }^{\circ} \mathrm{C}^{-1}$. Note that because the LGM represents a period of global cooling (Braconnot et al., 2012), the direction of change in $\mathrm{OLW}_{\text {cloud }}$ is opposite that shown in these figures.

positive longwave radiative-temperature response, which is consistent with the CFE results. All other GCM and CFE simulations have positive shortwave and negative longwave radiative-temperature response that are both smaller in magnitude than the IPSL-based simulations.

While the relative magnitude of the CFE radiativetemperature response results captures that of the original GCM results, the absolute magnitude of the radiativetemperature response is generally slightly reduced in CFE. We also present the results from a control $4 \times \mathrm{CO}_{2}$ UVic simulation, without the implementation of any cloud feedbacks (gray bar, Fig. 6). Here, the TOA shortwave radiative-temperature response is $\sim 0.40 \mathrm{~W} \mathrm{~m}^{-2}{ }^{\circ} \mathrm{C}^{-1}$ and the TOA longwave radiative-temperature response is $\sim-0.03 \mathrm{~W} \mathrm{~m}^{-2}{ }^{\circ} \mathrm{C}^{-1}$, whereas the average radiativetemperature response from the GCMs are $\sim 0.87$ and $\sim-0.55 \mathrm{~W} \mathrm{~m}^{-2}{ }^{\circ} \mathrm{C}^{-1}$, respectively. Therefore, the application of $\alpha_{\text {atm }}$ and OLW cloud $_{\text {feedbacks in CFE are prominent }}$ drivers in the spread of total TOA shortwave and longwave radiative-temperature response. In general, the GCMs show a greater reduction in global surface albedo with increasing temperature compared to the CFE (not shown). Therefore, the differences in surface albedo processes between the GCMs and CFE, likely explains some of the reduction in TOA shortwave radiative-temperature response magnitude in the CFE simulations.

\subsection{Radiative balance in CFE LGM simulations}

For the CFE LGM simulations, we calculate TOA shortwave and longwave radiative-temperature response at equilibrium conditions, averaged over the last 100 years of the LGM and ctlLGM experiments. Note that in this case the shortwave fluxes include forcing from prescribed ice sheets and therefore are not strictly speaking feedbacks. CFE generally captures the spread of the shortwave and longwave radiative-temperature response from the GCMs although it is slightly reduced (Fig. 6). The total imbalance seems to be smaller in CFE compared with most GCMs indicating that CFE is closer to equilibrium, perhaps because it was integrated longer. Thus, a larger remaining imbalance could contribute to the larger spread in the GCMs compared with CFE.

The absolute magnitude of the radiative-temperature response is mostly reduced in the CFE relative to the GCM simulations. Similar to the $4 \times \mathrm{CO}_{2}$ results, the IPSL-based simulations present the strongest shortwave and longwave radiative-temperature response. Conversely, the CNRMbased CFE simulation shows enhanced shortwave and longwave radiative-temperature response relative to those of the GCM, suggesting that non-cloud processes or differences in the forcings are likely important for this model. 

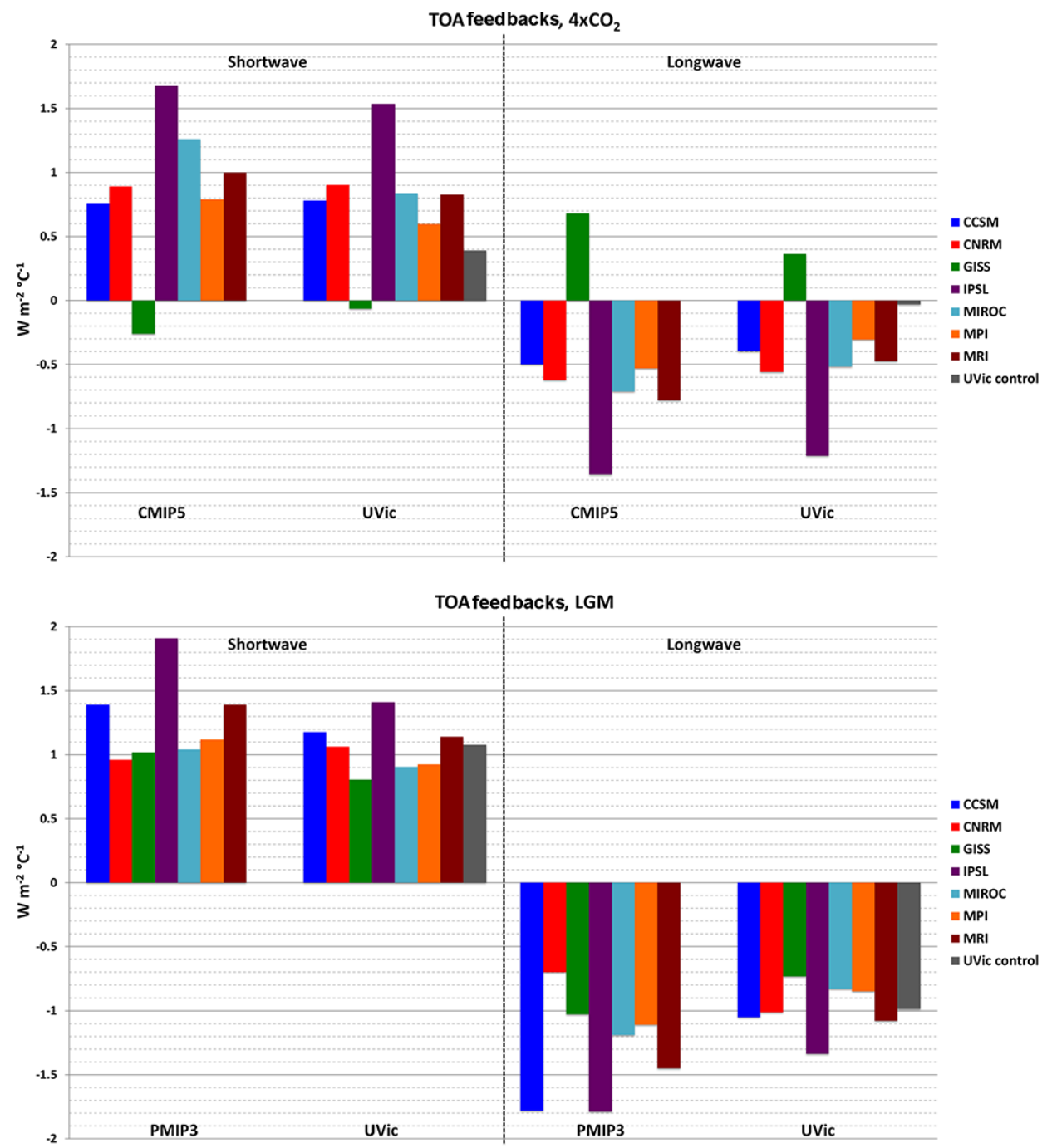

Figure 6. Comparison of $4 \times \mathrm{CO}_{2}$ (top) and LGM (bottom) top-of-the-atmosphere feedbacks calculated from raw CMIP5/PMIP3 output from each of the seven GCMs (CMIP5/PMIP3) and from UVic simulations using GCMs-derived cloud feedbacks (UVic). Shortwave feedbacks are shown on the left, longwave feedbacks on the right. Positive values designate an increased forcing TO the climate system with increased temperature (i.e., positive feedback). Feedbacks from the UVic control simulation without cloud feedbacks is shown in gray.

\subsection{Effect of CFE on modeled temperature evolution and spatial distribution}

As expected, the incorporation of cloud feedbacks into CFE has a direct impact on modeled surface temperature anomalies in perturbed experiments. For the $4 \times \mathrm{CO}_{2}$ experiments, global mean surface air temperature anomalies at the end of the 150 -year simulation range from $+3.9^{\circ} \mathrm{C}$ (GISS) to $+8.8^{\circ} \mathrm{C}$ (IPSL), where the control UVic simulation without cloud feedbacks results in a final anomaly of $+5.1{ }^{\circ} \mathrm{C}$ (Fig. 7). Only two CFE simulations (GISS and MRI) result in a year 150 temperature anomaly that is less than the UVic control, confirming that the $4 \times \mathrm{CO}_{2}$ net cloud feedbacks are generally positive (see above) and consistent with the anal- ysis of the individual models themselves (Vial et al., 2013; Tomassini et al., 2013).

The spatial variability in GCM cloud feedbacks (Figs. 2, 4) is also expressed in the $4 \times \mathrm{CO}_{2}$ zonal mean temperature anomalies (Fig. 7). All models show the effects of strong polar amplification by the end of the $4 \times \mathrm{CO}_{2}$ simulations, but the addition of cloud feedbacks to CFE appears to enhance this polar amplification in most cases. In addition, the change in temperature due to cloud feedbacks is not uniform for all models. For example, the CCSM-driven simulation presents some of the largest temperature anomalies in the southern high-latitudes but relatively reduced anomalies at the lowlatitudes, resulting in an overall global anomaly that is similar to the that of the control UVic simulation (Fig. 7). 

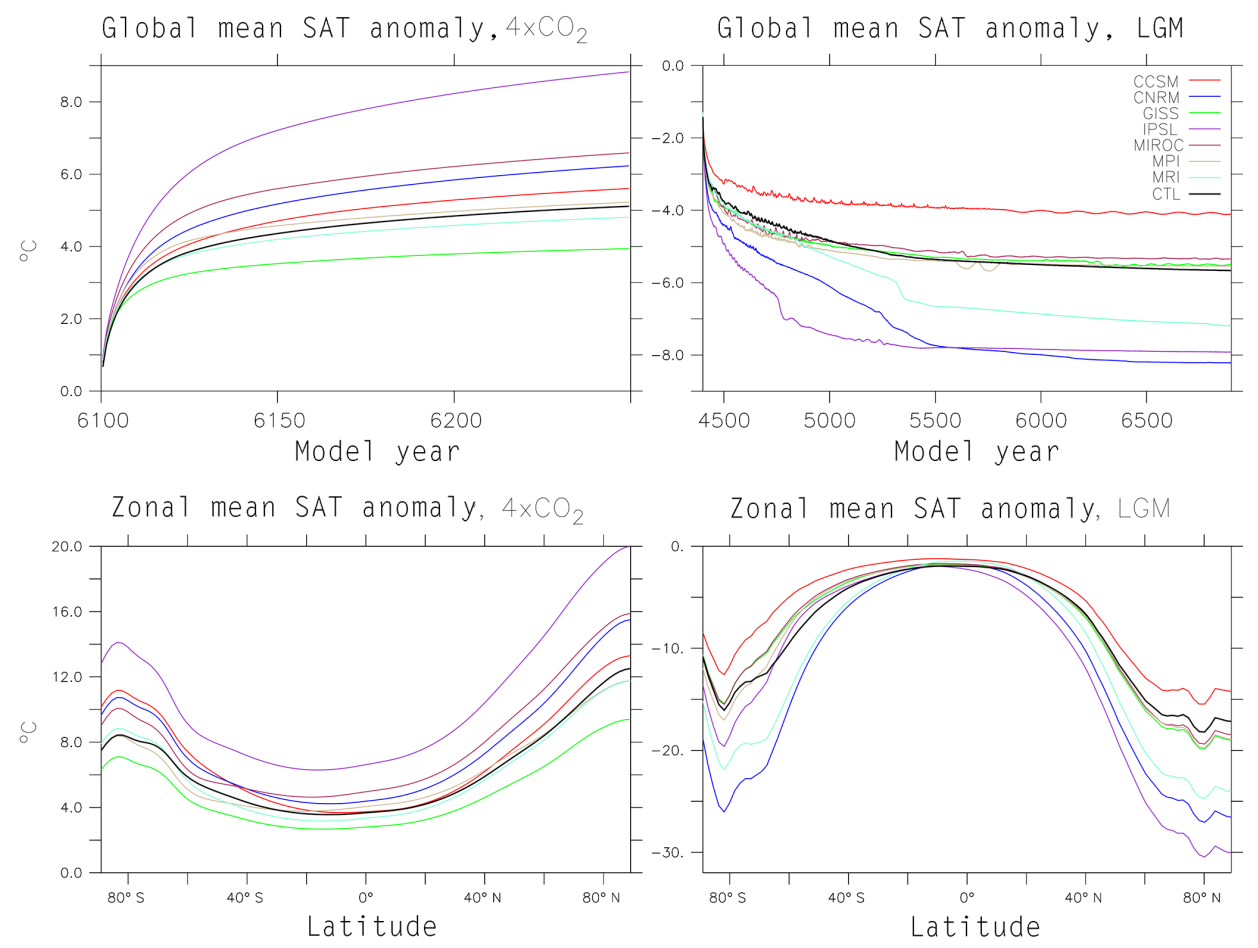

Figure 7. Global mean surface air temperature anomalies for the $4 \times \mathrm{CO}_{2}$ (upper left) and LGM (upper right) CFE simulations. Zonal mean surface air temperature anomalies from the CFE simulations, averaged over the last 10 years of the $4 \times \mathrm{CO}_{2}$ simulations (lower left) and the last 100 years of the LGM simulation (lower right).

For the LGM simulations, the global mean temperature change at the end of the simulation ranges from $-4.1^{\circ} \mathrm{C}$ (CCSM) to $-8.2^{\circ} \mathrm{C}(\mathrm{CNRM})$, whereas the control UVic simulation has a cooling of $5.7^{\circ} \mathrm{C}$ (Fig. 7). Nearly half of the UVic simulations show enhanced global mean cooling (CNRM, IPSL, and MRI) relative to the UVic control (Fig. 7), whereas the other four simulations show reduced cooling (CCSM, GISS, MIROC, and MPI). Again, zonal mean temperature anomalies at the LGM show that enhanced cloud feedbacks lead to enhanced polar amplification, but spatial differences in the magnitude of feedbacks may impact regional temperature change. For example, the CNRM-based simulation shows the strongest cooling in the southern high latitude, whereas the IPSL-based simulation has the largest cooling in the northern high latitudes (Fig. 7).

\subsection{Using CFE to estimate climate sensitivity}

Inter-model spread in GCM cloud feedbacks has been shown to have a large impact on the modeled sensitivity to perturbation in greenhouse gas radiative forcing (Fasullo and Trenberth, 2012; Andrews et al., 2012; Sherwood et al., 2014). To estimate the effect of the cloud feedbacks in CFE on global climate, we calculate effective equilibrium climate sensitivity $\left(\Delta T_{2 \mathrm{xC} \text {,eff }}\right)$ from the 150 -year $4 \times \mathrm{CO}_{2}$ simulations by regressing the global net downward heat flux at the TOA onto the change in temperature. The slope of this regres- sion is the climate response parameter $(\alpha)$ and the intercept is the $4 \times \mathrm{CO}_{2}$ forcing $\left(F_{4 \times \mathrm{CO}_{2}}\right)$ specific to each model (Gregory et al., 2004). These values can be used to estimate the effective equilibrium climate sensitivity to a doubling of $\mathrm{CO}_{2}$ by dividing the implied global $2 \mathrm{xCO}_{2}$ forcing $\left(F_{2 \times \mathrm{CO}_{2}}=F_{4 \times \mathrm{xO}_{2}} / 2\right)$ by $\alpha$ (Gregory et al., 2004). We calculate $\Delta T_{2 \times C}$,eff for both the raw GCM model output as well as the associated CFE simulations.

With the introduction of cloud feedbacks, CFE is able to capture much of the inter-model variability in climate sensitivity (Fig. 8). The seven GCMs sampled in this analysis show values of $\Delta T_{2 \times C}$,eff ranging from $2.15^{\circ} \mathrm{C}$ (GISS) to $4.10^{\circ} \mathrm{C}$ (IPSL), which agrees well with Andrews et al. (2012) for those models that were used in both studies. In the CFE simulations, $\Delta T_{2 \times C}$,eff values range from $2.34^{\circ} \mathrm{C}$ (GISS) to $7.00^{\circ} \mathrm{C}$ (IPSL). Again, the IPSL-based CFE simulation is a noticeable outlier, whereas all of the values of $\Delta T_{2 \times \mathrm{C} \text {,eff }}$ in CFE are more comparable to the values from the raw GCM output and the magnitude relative to each of the models is generally the same (Fig. 8). However, most of the CFE simulations show elevated $\Delta T_{2 \times C}$,eff relative to their GCM counterpart (Fig. 8). The $\Delta T_{2 \times C \text {,eff }}$ in the $4 \times \mathrm{CO}_{2}$ control UVic simulation (gray bar, Fig. 8 ) is $3.63{ }^{\circ} \mathrm{C}$, a value that is higher than most of the GCM results, suggesting that the control UVic climate sensitivity without explicit cloud feedbacks may already be higher than that of most of the sampled 


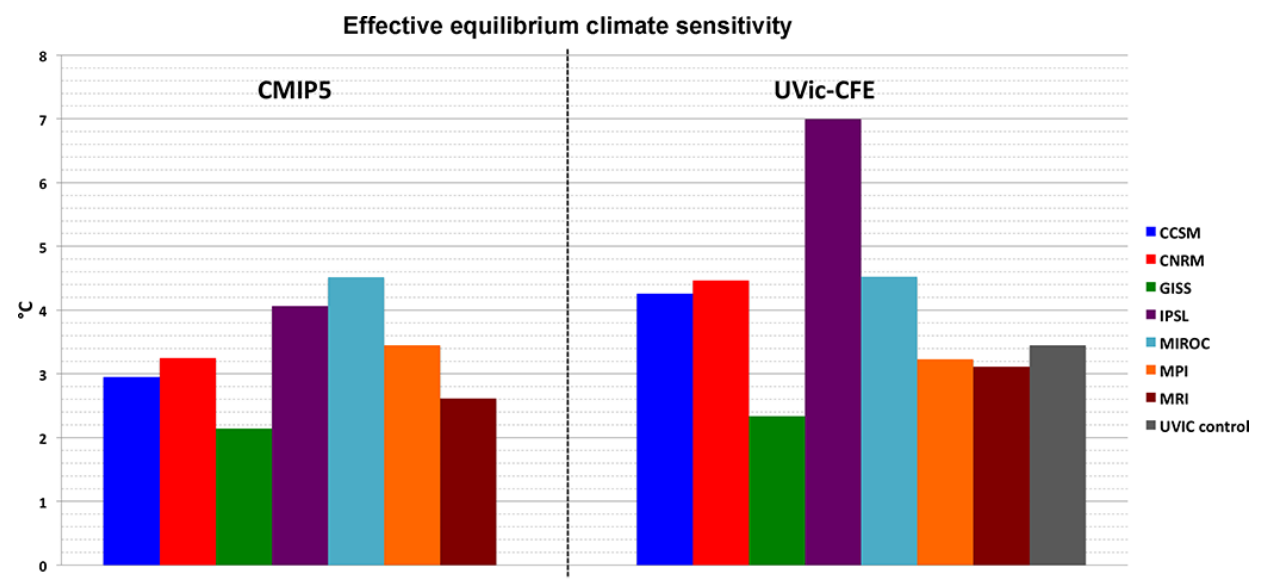

Figure 8. Comparison of effective equilibrium climate sensitivity $\left(\Delta T_{2 \mathrm{xC} \text {,eff }}\right)$ calculated from raw CMIP5 output from each of the seven GCMs (CMIP5) and from UVic simulations using GCMs-derived cloud feedbacks (UVic). $\Delta T_{2 \times C}$,eff from the UVic control simulation without cloud feedbacks is shown in gray.

GCMs. This suggests that the control UVic model's clearsky (without explicit clouds) feedbacks are larger than those of most GCMs. Adding the mostly positive cloud feedbacks thus makes the UVic model's climate sensitivities considerably larger than those of the GCMs. Clear-sky feedbacks in the UVic model could be tuned by, e.g., varying the coefficients of Eq. (6) if a better match with individual GCM's climate sensitivity was desired.

\section{Discussion and Conclusions}

The cloud feedbacks ( $\alpha_{\text {atm }}$ and $\mathrm{OLW}_{\text {cloud }}$ feedbacks) derived from the GCMs and employed in CFE are generally consistent between climate states $\left(4 \times \mathrm{CO}_{2}\right.$ vs. LGM) for each GCM, with some notable exceptions. For example, the $4 \mathrm{xCO}_{2} \alpha_{\text {atm }}$ feedbacks (Fig. 2) are generally consistent between models in showing a prominent negative feedback across the Southern Ocean, with CCSM being the only model with a positive $\alpha_{\text {atm }}$ feedback. However, for the LGM, the CCSM-derived $\alpha_{\text {atm }}$ feedback is negative along with all other models in general (Fig. 3). In addition, the $\alpha_{\text {atm }}$ feedbacks across the equatorial Pacific are not always consistent between climate states, with the CNRM-, GISS-, MIROC, and MPI-based fields showing a pronounced difference in the direction of the $\alpha_{\mathrm{atm}}$ feedback (Figs. 2, 3). Similarly, the $\mathrm{OLW}_{\text {cloud }}$ feedbacks across the equatorial Pacific and North Pacific differ in magnitude and direction between the climate states in nearly all models (Figs. 4, 5). These differences likely arise due to shifts in the ITCZ and Gulf Stream between climate states (Otto-Bliesner et al., 2006; Braconnot et al., 2007; Arbuszewski et al., 2013), and they suggest that such cloud feedbacks are not universal to all climate states. Furthermore, the cloud feedbacks derived from the GCMs should only be applied to a consistent climate state experiment when using CFE.
In general, the application of GCM-derived cloud feedbacks to CFE captures the changes in TOA radiative balance of the original GCMs, for both the $4 \times \mathrm{CO}_{2}$ and LGM experiments. Differences in total radiative feedbacks between each GCM and the associated CFE may exist for several reasons. First, the derivation of the cloud feedbacks are parameterized from the original GCM results and therefore may not be a perfect representation of the full complexity of cloud radiative forcing in each GCM. This is particularly the case for the shortwave cloud feedback, which is applied using a calculation of the $\alpha_{\text {atm }}$ feedback, which uses an assumption of a global mean atmospheric transmissivity (Eq. 3). The OLW $W_{\text {cloud }}$ feedbacks, on the other hand, are a direct calculation of the longwave cloud feedbacks from each GCM.

Second, total TOA feedbacks in CFE may not perfectly match those of the source GCMs because the resulting feedbacks are still partly controlled by the control radiative balance code of the UVic model. Other components of the Earth system, apart from clouds, impact the shortwave and longwave radiative balance in UVic, which may feedback on the simulated climate in a different manner than in the GCMs. For instance, the total TOA shortwave feedbacks include the effect of surface albedo change. Therefore, differences in vegetation and sea ice dynamics and their effect on surface albedo in the GCMs relative to UVic may help explain some of the differences in the shortwave feedbacks. Similarly, the longwave feedback in UVic is in part controlled by the SATbased parameterization of OLW in Eq. (6), which may be different from the clear-sky feedbacks in the GCMs

Third, the ratios of TOA flux and temperature changes shown in Fig. 6 include forcings (greenhouse gas for both $4 \times \mathrm{xO} 2$ and LGM and surface albedo for LGM). Therefore, differences in the forcings would also impact the total TOA "feedbacks". The forcings differ between the GCMs but are constant among the CFE experiments. In addition, our 
method of estimating cloud feedbacks neglects the effects of cloud masking and cloud rapid adjustment (Zelinka et al., 2013), which may explain some of the loss of spread in CFE compared with the GCMs.

However, despite the potential for differences in total radiative feedbacks, our results suggest that a simple parameterization of cloud shortwave and longwave feedbacks may be applied to UVic to generally capture dominant intermodel spread in total radiative feedbacks. This result confirms that cloud feedbacks dominate the multi-model uncertainty in GCM radiative balance (Soden and Held, 2006; Dufrense and Bony, 2008; Tomassini et al., 2013; Vial et al., 2013). The addition of GCM-derived cloud feedbacks to the UVic leads to only small increases in computational expense, while capturing an important component of the Earth's radiative balance that is otherwise lacking in the default UVic model. Indeed, the inclusion of cloud feedbacks leads to a large spread in surface air temperature anomalies for both the $4 \times \mathrm{CO}_{2}$ and LGM experiments (Fig. 7). In addition, spatial variability in the cloud feedbacks (Figs. 2-5) leads to some differences in the latitudinal distribution of this temperature change (Fig. 7), suggesting that certain regional cloud changes may be important on the global scale. Differences in Equator-pole temperature contrast do to cloud feedbacks in CFE could impact ocean heat transport in the model.

The application of cloud feedbacks in CFE provides an important source of inter-model uncertainty that is present in CMIP5/PMIP3. Recent model-data comparisons suggest that the state-of-the-art CMIP5 simulations capture important cloud feedbacks across the observational record (Norris et al., 2016), providing assurance that the feedbacks in CFE are also within the range of observations. However, as model physics of cloud dynamics and spatial distribution continue to improve in future GCM simulations, the GCM cloud radiative effects can again be applied in CFE ensemble analyses to emulate the multi-model uncertainty in cloud feedbacks.

Finally, we confirm that the cloud feedbacks in each of the GCMs plays a prominent role in determining the resulting climate sensitivity of each simulation (Fasullo and Trenberth, 2012; Andrews et al., 2012; Sherwood et al., 2014). By incorporating cloud feedbacks into CFE, we generally capture the relative spread $\Delta T_{2 \times C \text {,eff }}$ of the GCMs (Fig. 8). The absolute

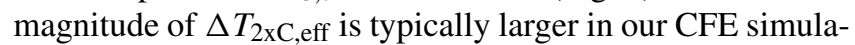
tions relative to each of the GCMs. Since net cloud feedbacks are generally positive in CMIP5 (Vial et al., 2013; Tomassini et al., 2013), the addition of these radiative feedbacks may require a revision of the overall radiative balance in CFE. Specifically, future versions of CFE may consider the effects of cloud masking and rapid adjustment in the cloud feedback parameterization (Zelinka et al., 2013). Conversely, the full radiative balance may be adjusted through an enhanced OLW parameterization by slight modification to the constants in Eq. (6). This method of has been applied to UVic to effectively adjust $\Delta T_{2 \times C \text {,eff }}$ (Schmittner et al., 2011). The CFE is currently being applied to a study of climate sensitivity using paleoclimate reconstructions (Ullman et al., 2017).

\section{Code and data availability}

CFE v1.0 model code, associated cloud feedback input files, and other relevant data files are available as a Supplement to this manuscript. See the README file in the Supplement for description of contents.

\section{The Supplement related to this article is available online at doi:10.5194/gmd-10-945-2017-supplement.}

Competing interests. The authors declare that they have no conflict of interest.

Acknowledgements. This work was supported by a grant from the National Science Foundation's Paleoclimate Perspectives on Climate Change (P2C2) program (award number 1204243). The authors thank two anonymous referees, along with the editorial staff of Geoscientific Model Development for their constructive comments and suggestions.

Edited by: K. Gierens

Reviewed by: two anonymous referees

\section{References}

Andrews, T., Gregory, J. M., Webb, M. J., and Taylor, K. E.: Forcing, feedbacks and climate sensitivity in CMIP5 coupled atmosphere-ocean climate models, Geophys. Res. Lett., 39, L09712, doi:10.1029/2012GL051607, 2012.

Arbuszewski, J., deMenocal, P. B., Cléroux, C., Bradtmiller, L., and Mix, A.: Meridional shifts of the Atlantic intertropical convergence zone since the Last Glacial Maximum, Nat. Geosci., 6, 959-962, doi:10.1038/NGEO1961, 2013.

Barkstrom, B. R.: The earth radiation budget experiment (ERBE), B. Am. Meteorol. Soc., 65, 1170-1185, 1984.

Barkstrom, B. R. and Smith, G. L.: The earth radiation budget experiment: Science and implementation, Rev. Geophys., 24, 379390, 1986.

Braconnot, P., Otto-Bliesner, B., Harrison, S., Joussaume, S., Peterchmitt, J.-Y., Abe-Ouchi, A., Crucifix, M., Driesschaert, E., Fichefet, Th., Hewitt, C. D., Kageyama, M., Kitoh, A., Loutre, M.-F., Marti, O., Merkel, U., Ramstein, G., Valdes, P., Weber, L., Yu, Y., and Zhao, Y.: Results of PMIP2 coupled simulations of the Mid-Holocene and Last Glacial Maximum - Part 2: feedbacks with emphasis on the location of the ITCZ and mid- and high latitudes heat budget, Clim. Past, 3, 279-296, doi:10.5194/cp-3-279-2007, 2007. 
Braconnot, P., Harrison, S. P., Otto-Bliesner, B., Abe-Ouchi, A., Jungclaus, J., and Petterschmitt, J.-Y.: The Paleoclimate Modeling Intercomparison Project contribution to CMIP5, CLIVAR Exchanges, 16, 15-19, 2011.

Braconnot, P., Harrison, S. P., Kageyama, M., Bartlein, P. J., Masson-Delmotte, V., Abe-Ouchi, A., Otto-Bliesner, B., and Zhao, Y.: Evaluation of climate models using palaeoclimatic data, Nature Climate Change, 2, 417-424, 2012.

Cess, R. D., Zhang, M., Wang, P. H., and Wielicki, B. A.: Cloud structure anomalies over the tropical Pacific during the 1997/98 El Nino, Geophys. Res. Lett., 28, 4547-4550, 2001.

Cox, P. M.: Description of the TRIFFID dynamic global vegetation model, Technical Note 24, Hadley Centre, United Kingdom Meteorological Office, Bracknell, UK, 1-16, 2001.

Crucifix, M., Loutre, M. F., Tulkens, P., Fichefet, T., and Berger, A.: Climate evolution during the Holocene: A study with an Earth system model of intermediate complexity, Clim. Dynam., 19, 4360, 2002.

Driesschaert, E.: Climate change over the next millennia using LOVECLIM, a new Earth system model including the polar ice sheets, $\mathrm{PhD}$ thesis, 214 pp., Univ. Catholique de Louvain, Louvain-la-Neuve, Belgium, 2005.

Dufresne, J. L. and Bony, S.: An assessment of the primary sources of spread of global warming estimates from coupled atmosphereocean models, J. Climate, 21, 5135-5144, 2008.

Eby, M., Weaver, A. J., Alexander, K., Zickfeld, K., Abe-Ouchi, A., Cimatoribus, A. A., Crespin, E., Drijfhout, S. S., Edwards, N. R., Eliseev, A. V., Feulner, G., Fichefet, T., Forest, C. E., Goosse, H., Holden, P. B., Joos, F., Kawamiya, M., Kicklighter, D., Kienert, H., Matsumoto, K., Mokhov, I. I., Monier, E., Olsen, S. M., Pedersen, J. O. P., Perrette, M., Philippon-Berthier, G., Ridgwell, A., Schlosser, A., Schneider von Deimling, T., Shaffer, G., Smith, R. S., Spahni, R., Sokolov, A. P., Steinacher, M., Tachiiri, K., Tokos, K., Yoshimori, M., Zeng, N., and Zhao, F.: Historical and idealized climate model experiments: an intercomparison of Earth system models of intermediate complexity, Clim. Past, 9, 11111140, doi:10.5194/cp-9-1111-2013, 2013.

Fasullo, J. T. and Trenberth, K. E.: The annual cycle of the energy budget. Part I: Global mean and land-ocean exchanges, J. Climate, 21, 2297-2312, 2008.

Fyke, J. and Eby, M.: Comment on "Climate sensitivity estimated from temperature reconstructions of the Last Glacial Maximum", Science, 337, 1294-1294, 2012.

Gregory, J. M., Ingram, W. J., Palmer, M. A., Jones, G. S., Stott, P. A., Thorpe, R. B., Lowe, J. A., Johns, T. C., and Williams, K. D.: A new method for diagnosing radiative forcing and climate sensitivity, Geophys. Res. Lett., 31, L03205, doi:10.1029/2003GL018747, 2004.

Hartmann, D. L. and Short, D. A.: On the use of earth radiation budget statistics for studies of clouds and climate, J. Atmos. Sci., 37, 1233-1250, 1980.

Hartmann, D. L., Ockert-Bell, M. E., and Michelsen, M. L.: The effect of cloud type on Earth's energy balance: Global analysis, J. Climate, 5, 1281-1304, 1992.

IPCC Working Group I: Climate Change 2001: The Scientific Basis, Contribution of Working Group I to the Third Assessment Report of the Intergovernmental Panel on Climate Change, edited by: Houghton, J. T., Ding, Y., Griggs, D. J., Noguer, M., van der Lin- den, P. J., Dai, X., Maskell, K., and Johnson, C. A., Cambridge University Press, 2001.

Joos, F., Prentice, I. C., Sitch, S., Meyer, R., Hooss, G., Plattner, G.K., Gerber, S., and Hasselmann, K.: Global warming feedbacks on terrestrial carbon uptake under the IPCC emission scenarios, Global Biogeochem. Cy., 15, 891-907, 2001.

Loeb, N. G., Wielicki, B. A., Doelling, D. R., Smith, G. L., Keyes, D. F., Kato, S., Manalo-Smith, N., and Wong, T.: Toward optimal closure of the Earth's top-of-atmosphere radiation budget, J. Climate, 22, 748-766, 2009.

Lu, J., Vecchi, G. A., and Reichler, T.: Expansion of the Hadley cell under global warming, Geophys. Res. Lett., 34, L06805, doi:10.1029/2006GL028443, 2007.

Marvel, K., Schmidt, G. A., Miller, R. L., and Nazarenko, L. S.: Implications for climate sensitivity from the response to individual forcings, Nature Climate Change, 6, 386-389, doi:10.1038/NCLIMATE2888, 2016.

Meissner, K. J., Weaver, A. J., Matthews, H. D., and Cox, P. M.: The role of land surface dynamics in glacial inception: a study with the UVic Earth System Model, Clim. Dynam., 21, 515-537, 2003.

Muglia, J. and Schmittner, A.: Glacial Atlantic overturning increased by wind stress in climate models, Geophys. Res. Lett., 42, 9862-9868, doi:10.1002/2015GL064583, 2015.

NOAA National Centers for Environmental Information, State of the Climate: Global Analysis for Annual 2015, published online January 2016, available at: http://www.ncdc.noaa.gov/sotc/ global/201513, last access: 6 July 2016.

Norris, J. R., Allen, R. J., Evan, A. T., Zelinka, M. D., O’Dell, C. W., and Klein, S. A.: Evidence for climate change in the satellite cloud record, Nature, 536, 72-75, 2016.

Otto-Bliesner, B. L., Brady, E. C., Clauzet, G., Tomas, R., Levis, S., and Kothavala, Z.: Last glacial maximum and Holocene climate in CCSM3, J. Climate, 19, 2526-2544, 2006.

Peltier, W. R.: Global glacial isostasy and the surface of the ice-age Earth: the ICE-5G (VM2) model and GRACE, Annu. Rev. Earth Planet. Sci., 32, 111-149, 2004.

Plattner, G.-K., Joos, F., Stocker, T. F., and Marchal, O.: Feedback mechanisms and sensitivities of ocean carbon uptake under global warming, Tellus, 53B, 564-592, 2001.

Ramanathan, V., Cess, R. D., Harrison, E. F., Minnis, P., Barkstrom, B. R., Ahmad, E., and Hartmann, D.: Cloud-Radiative Forcing and Climate: Results from the Earth Radiation Budget Experiment, Science, 243, 57-63, 1989.

Schmittner, A., Urban, N. M., Shakun, J. D., Mahowald, N. M., Clark, P. U., Bartlein, P. J., Mix, A. C., and Rosell-Melé, A.: Climate sensitivity estimated from temperature reconstructions of the Last Glacial Maximum, Science, 334, 1385-1388, 2011.

Sherwood, S. C., Bony, S., and Dufresne, J. L.: Spread in model climate sensitivity traced to atmospheric convective mixing, $\mathrm{Na}$ ture, 505, 37-42, 2014.

Soden, B. J. and Held, I. M.: An assessment of climate feedbacks in coupled ocean-atmosphere models, J. Climate, 19, 3354-3360, 2006.

Taylor, K. E., Stouffer, R. J., and Meehl, G. A.: An overview of CMIP5 and the experiment design, B. Am. Meteorol. Soc., 93, 485-498, 2012. 
Thompson, S. L. and Warren, S. G.: Parameterization of outgoing infrared radiation derived from detailed radiative calculations, J. Atmos. Sci., 39, 2667-2680, 1982.

Tomassini, L., Geoffroy, O., Dufresne, J.-L., Idelkadi, A., Cagnazzo, C., Block, K., Mauritsen, T., Giorgetta, M., and Quaas, J.: The respective roles of surface temperature driven feedbacks and tropospheric adjustment to $\mathrm{CO}_{2}$ in CMIP5 transient climate simulations, Clim. Dynam., 41, 3103-3126, doi:10.1007/s00382-013-1682-3, 2013.

Tselioudis, G., Rossow, W. B., and Rind, D.: Global patterns of cloud optical thickness variation with temperature, J. Climate, 5, 1484-1495, 1992.

Ullman, D. J., Schmittner, A., and Urban, N. M.: A new estimate of climate sensitivity using Last Glacial Maximum model-data constraints that includes parametric, feedback, and proxy uncertainties, in preparation, 2017.

Vial, J., Dufresne, J. L., and Bony, S.: On the interpretation of intermodel spread in CMIP5 climate sensitivity estimates, Clim. Dynam., 41, 3339-3362, 2013.
Weaver, A. J., Eby, M., Wiebe, E., Bitz, C. M., Duffy, P. B., Ewen, T. L., Fanning, A. F., Holland, M. M., MacFadyen, A., Matthews, H. D., Meissner, K. J., Saenko, O., Schmittner, A., Wang, H., and Yoshimori, M.: The UVic Earth System Climate Model: model description, climatology, and applications to past, present and future climates, Atmosphere-Ocean, 39, 361-428, 2001.

Wielicki, B. A., Barkstrom, B. R., Harrison, E. F., Lee III, R. B., Louis Smith, G., and Cooper, J. E.: Clouds and the Earth's Radiant Energy System (CERES): An earth observing system experiment, B. Am. Meteorol. Soc., 77, 853-868, 1996.

Yin, J. H. and Battisti, D. S.: The importance of tropical sea surface temperature patterns in simulations of Last Glacial Maximum climate, J. Climate, 14, 565-581, 2001.

Zelinka, M. D., Klein, S. A., and Hartmann, D. L.: Computing and partitioning cloud feedbacks using cloud property histograms. Part I: Cloud radiative kernels, J. Climate, 25, 3736-3754, 2012.

Zelinka, M. D., Klein, S. A., Taylor, K. E., Andrews, T., Webb, M. J., Gregory, J. M., and Forster, P. M.: Contributions of different cloud types to feedbacks and rapid adjustments in CMIP5, J. Climate, 26, 5007-5027, 2013. 